\title{
光催化有机物偶联/芳构化放氢反应研究进展
}

\author{
陈锋陈浩吴庆安罗书平* \\ (浙江工业大学化学工程学院 绿色化学合成技术国家重点实验室培育基地 杭州 310014)
}

\begin{abstract}
摘要 光催化氧化还原反应具有绿色、高效、安全等优势, 已经在有机化学中得到广泛关注. 介绍了基于光催化的偶 联/芳构化放氢反应，通过使用光催化剂/催化剂的双催化体系，可用于光催化有机碳一碳和碳-杂原子成键反应，且反应 中氢气是唯一的副产物. 强调了有机光氧化还原体系的构建与催化机理.
\end{abstract}

关键词 光催化; 有机物放氢反应; 偶联反应; 芳构化反应

\section{Progress on the Photocatalytic Organic Hydrogen-Evolution Coupling/Aromatization Reaction}

\author{
Chen, Feng Chen, Hao Wu, Qing'an Luo, Shuping* \\ (State Key Laboratory Breeding Base of Green Chemistry-Synthesis Technology, College of Chemical Engineering, \\ Zhejiang University of Technology, Hangzhou 310014)
}

\begin{abstract}
The photocatalytic redox reactions have been widely concerned in organic chemistry due to their green, efficiency and safety. In this review, the cross-coupling/aromatization reactions are described based on photocatalytic organic hydrogenevolution, which can be used to build organic carbon-carbon and carbon-heteroatom bonds by using a photocatalyst/catalyst dual catalytic system. Hydrogen is the only by-product in these reactions. The system and catalytic mechanisms of organic photocatalytic redox reaction are highlighted.
\end{abstract}

Keywords photocatalysis; organic hydrogen-evolution reaction; coupling reaction; aromatization reaction

过去一个世纪, 光介入催化 (light-mediated catalysis)的发展和应用使得有机化学中的各种非传统成键反 应成为可能 ${ }^{[1]}$. 最近, 光催化合成开始复兴, 通过一系 列新的激活模式为导向, 引入了各种形式的新的成键方 式和合成策略 ${ }^{[2 \sim 4]}$. 光催化合成通过将光能选择性地转 移到特别设计的光催化剂(photocatalyst)中，被光激发的 光催化剂能够引导底物、试剂或者催化剂参与到传统的 热控制反应无法实现的独特的反应路径里 ${ }^{\left[{ }^{[} \sim 10\right]}$.

开发绿色高效、原子经济性高的 C-C、C-X(杂原 子)键构筑策略是有机合成化学领域重要的研究内容之 一. 在光催化领域, 通过以光能为直接能量源, 用以脱 氢来形成如 $\mathrm{C}-\mathrm{C} 、 \mathrm{C}-\mathrm{X}$ 键的反应和芳构化的反应受到 了人们的关注. 传统的构建 C- $\mathrm{C} 、 \mathrm{C}-\mathrm{X}$ 键的反应一般 需要化学计量的金属(准金属)试剂和有机卤化物作为原 料, 并且伴随着化学计量的盐作为副产物 ${ }^{[1 \sim 17]}$. 而在有
机光合成领域，近几年发展的一类基于光催化的 $\mathrm{C}-\mathrm{H}$ 官能化和芳构化的反应受到了人们关注. 以光能为直接 能量源, 光催化剂/催化剂构建的双催化体系催化 $\mathrm{C}-\mathrm{H}$ 键脱氢形成 $\mathrm{H}_{2}$ 作为副产物, 这类反应无需外加氧化剂, 也不需要化学计量的牺牲剂, 可以实现 $\mathrm{C}-\mathrm{C}, \mathrm{C}-\mathrm{X}$ 键 的生成或芳构化，具有原子经济高、高效和环境友好等 优势(Schemes 1，2). 在这篇综述里，我们将讨论这些

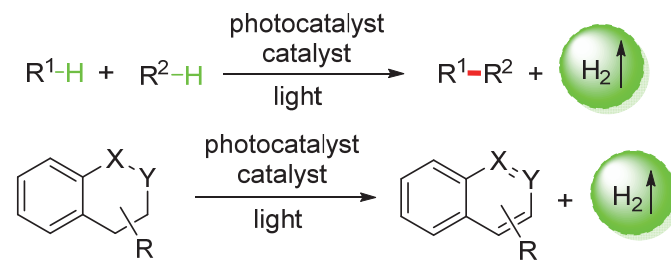

图式 1 光催化放氢反应简介

Scheme 1 Introduction of photocatalytic hydrogen-evolution

\footnotetext{
* Corresponding author. E-mail: Luoshuping@zjut.edu.cn

Received September 16, 2019; revised October 18, 2019; published online November 1, 2019.

Project supported by the National Natural Science Foundation of China (No. 21376222) and the Natural Science Foundation of Zhejiang Province (No. LY18B060011).

国家自然科学基金(No. 21376222)和浙江省自然科学基金(No. LY18B060011)资助项目.
} 
<smiles></smiles>

$\mathrm{ArC}^{+}-\mathrm{Mes} \mathrm{ClO}_{4}^{-}$ $E_{\text {red }}^{*}=2.18 \mathrm{~V}$

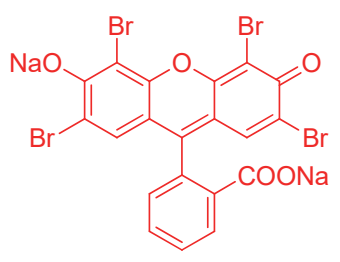

eosin $Y$ $E_{\text {red }}^{*}=1.23 \mathrm{~V}$

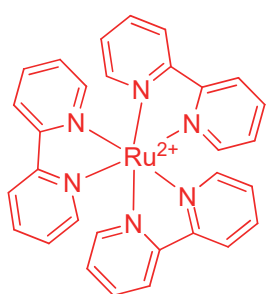

$\mathrm{Ru}(\mathrm{bpy})_{3}^{2+}$ $E_{\text {red }}^{\star}=1.48 \mathrm{~V}$ (对应 Ru(bpy) ${ }_{3}^{2+} \mathrm{Cl}_{2}$ )

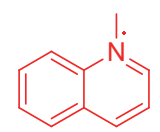

$\mathrm{QuH}^{+}$

$E_{\text {red }}^{*}=2.46 \mathrm{~V}$

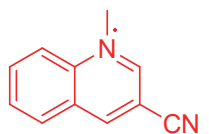

$\mathrm{QuCN}^{+}$

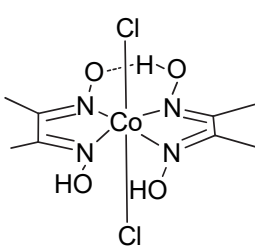

Co'l'( $\mathrm{dmgH})_{2} \mathrm{Cl}_{2}$

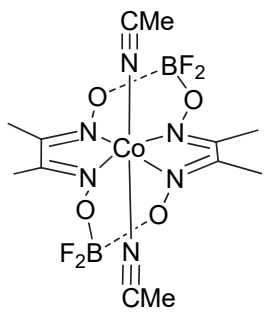

$\mathrm{Col}\left(\mathrm{dmgBF}_{2}\right)_{2}\left(\mathrm{CH}_{3} \mathrm{CN}\right)_{2}$

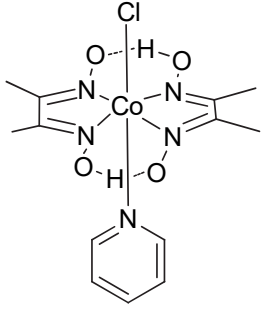

$\mathrm{Co}^{\prime \prime \prime}(\mathrm{dmgH})_{2} \mathrm{pyCl}$

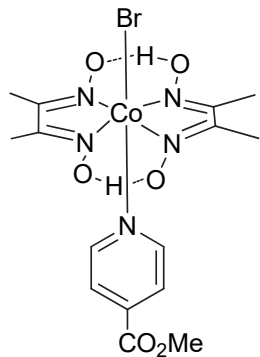

$\mathrm{Co}^{\text {III }}(\mathrm{dmgH})_{2}\left(4-\mathrm{CO}_{2} \mathrm{Me}-\mathrm{py}\right) \mathrm{Br}$

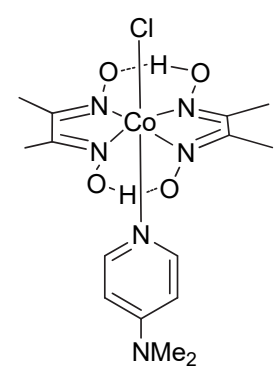

$\mathrm{Co}^{\prime \prime \prime}(\mathrm{dmgH})_{2}\left(4-\mathrm{NMe}_{2}-\mathrm{py}\right) \mathrm{Cl}$

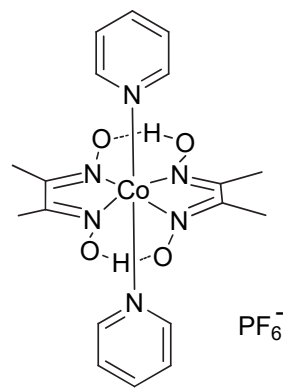

$\mathrm{Co}^{\prime \prime}(\mathrm{dmgH})_{2} \mathrm{py}_{2} \mathrm{PF}_{6}$

图式 2 常用于光催化放氢反应的光催化剂和钴肜催化剂

Scheme 2 Photocatalysts and Co catalysts commonly used in photocatalytic hydrogen-evolution coupling reaction

具有广泛应用前景的光催化反应, 以显示光催化碳氢活 化放氢反应的独特性和新颖性.

\section{1 活化 $\mathrm{sp}^{3}$-碳的交叉偶联放氢反应}

$\mathrm{C}-\mathrm{H}$ 活化因其原子经济性和步骤经济性而得到广 泛关注, $\mathrm{C}-\mathrm{H}$ 活化官能团化反应在构建 $\mathrm{C}-\mathrm{C}$ 键和 $\mathrm{C}-$ $X$ 键方面是最直接、高效和绿色的途径 ${ }^{[11 ~ 17]}$. 但由于 $\mathrm{sp}^{3}$-碳的反应情性等限制使得 $\mathrm{C}\left(\mathrm{sp}^{3}\right)-\mathrm{H}$ 活化具有很大 的难度和挑战性. 光催化氧化偶联放氢反应是实现活化 $\mathrm{sp}^{3}$-碳参与偶联反应的有效策略. 通过光催化剂对底物 上的杂原子 $(\mathrm{O} 、 \mathrm{~N}$ 原子)或是富电子基团氧化，可以实现 $\alpha$-sp - $^{3}$ 碳的活化, 从而可以与亲核试剂反应生成偶联产 物, 反应中只生成 $\mathrm{H}_{2}$ 作为副产物(Scheme 3 ).

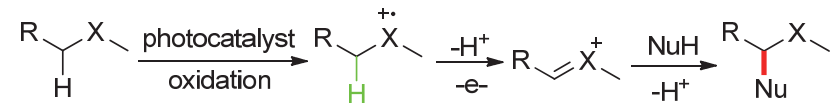

图式 3 对 $\mathrm{sp}^{3}$-碳的光催化活化策略

Scheme 3 Photocatalytic activation strategy for $\mathrm{sp}^{3}$-carbon
2013 年, 吴骊珠课题组 ${ }^{[21]}$ 报道了基于 [曙红 Y] (eo$\sin \mathrm{Y}$ )光催化剂和负载于石墨烯的 $\mathrm{RuO}_{2}$ 纳米复合材料 $\left(\mathrm{G}-\mathrm{RuO}_{2}\right)$ 的双催化体系催化 $N$-苯基-1,2,3,4-四氢异喹啉 (1)和吲哚(2)之间的交叉偶联放氢反应. 在 $\lambda>450 \mathrm{~nm}$ 高 压录灯下反应 $20 \mathrm{~h}$, 可以以高达 $98 \%$ 的收率得到偶联产 物 3a, $\mathrm{H}_{2}$ 是唯一的副产物(Scheme $4 \mathrm{~A}$ ).

在该光催化偶联放氢反应体系中, 以 $\mathrm{RuO}_{2}$ 纳米复 合材料 $\left(\mathrm{G}-\mathrm{RuO}_{2}\right)$ 为非均相催化剂一定程度上限制了该 合成方式的适用性. 通过使用双乙二醛肜配体与氯化钻 或醋酸钻反应可以合成一系列的钴肜催化剂 ${ }^{[22]}$. Scheme 2 列出了一部分较常见的钴肟催化剂. 由于钴肜催化剂 成本低廉, 稳定性好, 同时拥有理想可调节的氧化还原 电位, 因而被作为质子还原催化剂广泛用于光致产氢体 系中 ${ }^{[23 ~ 25]}$. Artero 和 Peters 课题组通过电化学催化产氢 研究发现, 钴肟配合物在催化产氢过程中可以形成活性 $\mathrm{Co}(\mathrm{I})$ 物种，该物种可以捕获质子并通过均裂或异裂放 出氢气 ${ }^{[26 ~ 28]}$. 钴肜催化剂独特的特性使其具有用于有 机合成的潜力. 
A

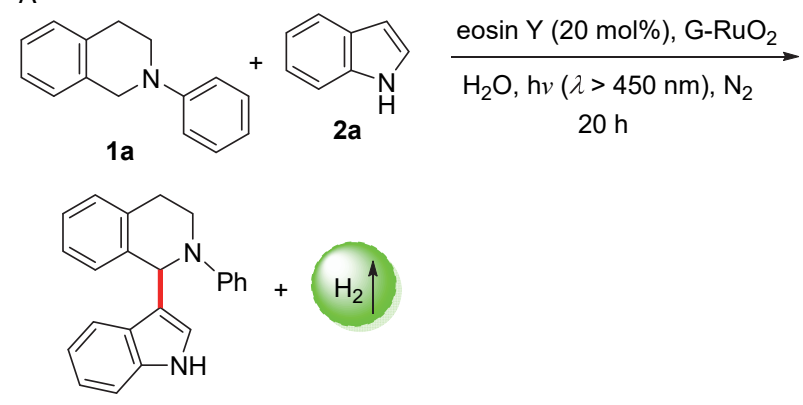

3a, $98 \% \quad \mathrm{H}_{2}: 90 \%$

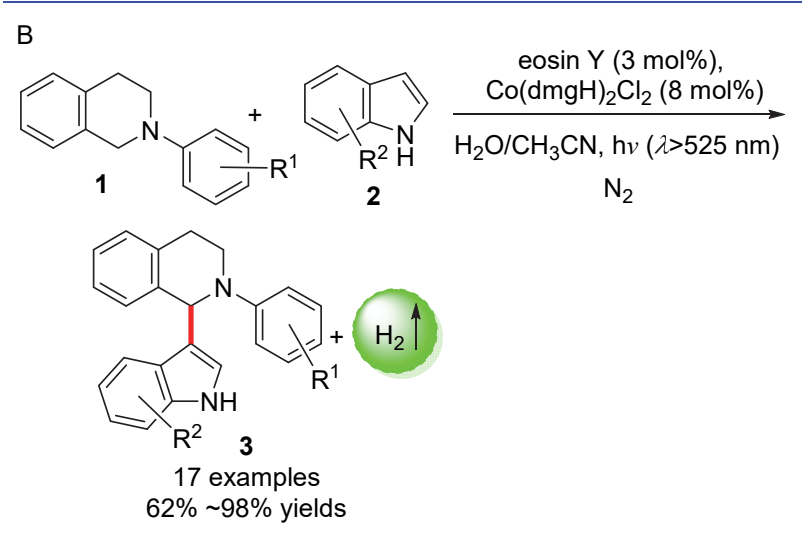

图式 4 (A) 以 $\mathrm{G}-\mathrm{RuO}_{2}$ 为催化剂的光催化偶联放氢反应和(B) 以 $\mathrm{Co}(\mathrm{dmgH})_{2} \mathrm{Cl}_{2}$ 为催化剂时的光催化偶联放氢反应

Scheme 4 (A) Photocatalytic hydrogen-evolution coupling with $\mathrm{G}-\mathrm{RuO}_{2}$ as catalyst, and (B) photocatalytic hydrogen-evolution coupling with $\mathrm{Co}(\mathrm{dmgH})_{2} \mathrm{Cl}_{2}$ as catalyst

2014 年, 吴骊珠课题组 ${ }^{[29]}$ 通过使用钴肜催化剂 $\left[\mathrm{Co}(\mathrm{dmgH})_{2} \mathrm{Cl}_{2}\right]$ 代替了贵金属催化剂 $\mathrm{G}-\mathrm{RuO}_{2}$ 以捕获因 底物 $\mathrm{C}-\mathrm{H}$ 键断裂产生的电子和质子(Scheme 4B), 以 [eosin $\mathrm{Y}$ ]为光敏催化剂成功实现了均相体系的 $N$-苯基 四氢异喹啉和吲哚之间的交叉偶联放氢反应. 研究表明 有机溶剂和水对反应的进行都很重要, 偶联产物收率最

高达 98\%.

该反应机理如 Scheme 5 所示. 光激发下, [eosin Y] 被光激发为单重激发态后快速转变成三重激发态. 叔胺 底物可与三重激发态的 $[\operatorname{eosin} \mathrm{Y}]^{*}$ 进行单电子转移从而

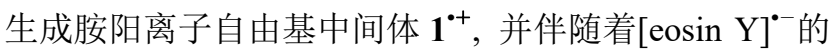
生成. 同位素标定实验发现生成的 $\mathrm{H}_{2}$ 质子主要来源于 水, 证实了水也参与了反应过程. [eosin $\mathrm{Y}]^{\bullet-}$ 可与 $\mathrm{Co}$ 催 化剂通过电子交换再生到初始状态，中间体 $\mathbf{1}^{\cdot+}$ 可以被 $\mathrm{Co}(\mathrm{II})$ 进一步氧化生成亚胺鎓中间体并放出质子, 亚胺 鎓中间体可以有效地与亲核试剂反应以提供偶联产物 3. 在反应中, Co 催化剂通过将光催化剂和 $\mathbf{1}^{-+}$氧化并对 $\mathrm{H}$ 质子还原实现了反应循环.

吴骊珠等 ${ }^{[30}$ 通过进一步研究发现, 通过向反应体 系里加入质子捕获剂(硝基苯), 可以利用生成的 $\mathrm{H}_{2}$ 以一 锅法原位生成苯胺，同时对原反应收率基本没有影响. 在这里, 钴肜催化剂同时作为了氢化试剂(hydrogenation catalyst)还原了硝基.

2015 年, 吴骊珠课题组 ${ }^{[31]}$ 报道了一种对 $\alpha$-氨基酸 衍生物直接 $\mathrm{C}-\mathrm{H}$ 活化的交叉偶联放氢反应, 但由于反 应中使用的是仲胺底物而非叔胺底物, 活化需要具备更 高氧化能力的光催化剂. 此外, 反应体系必须无水以防 止反应中的亚胺中间体的分解. 最后, 作者使用了 $\left[\mathrm{Ru}(\mathrm{bpy})_{3}\left(\mathrm{PF}_{6}\right)_{2}\right]$ 光催化剂和 $\left[\mathrm{Co}(\mathrm{dmgH})_{2} \mathrm{pyCl}\right]$ 催化剂的 双催化体系, 成功实现了含对甲氧基苯基结构的氨基酸 衍生物和吲哚类底物的偶联反应, 最高偶联产物收率达 90\% (Scheme 6). 底物扩展表明, 氨基酸底物上的对甲 氧基苯基的存在对反应的进行是必须的，此外将吲哚类 底物换成 $\beta$-酩酸酯底物, 也能以高收率得到偶联产物. 机理研究表明, 该反应产生的 $\mathrm{H}_{2}$ 的质子来源于参与反 应的两个底物, 该反应也是通过 3 个单电子转移过程完 成了底物的活化以及光催化剂/催化剂的再生(Scheme 7).

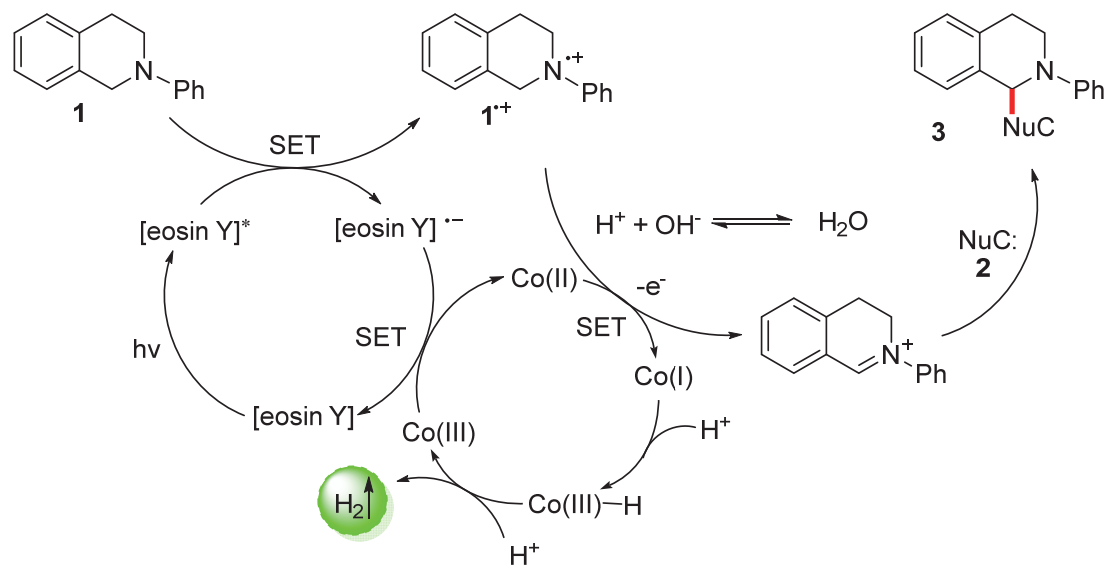

图式 5 双催化体系反应机理

Scheme 5 Reaction mechanism of the dual catalytic system 


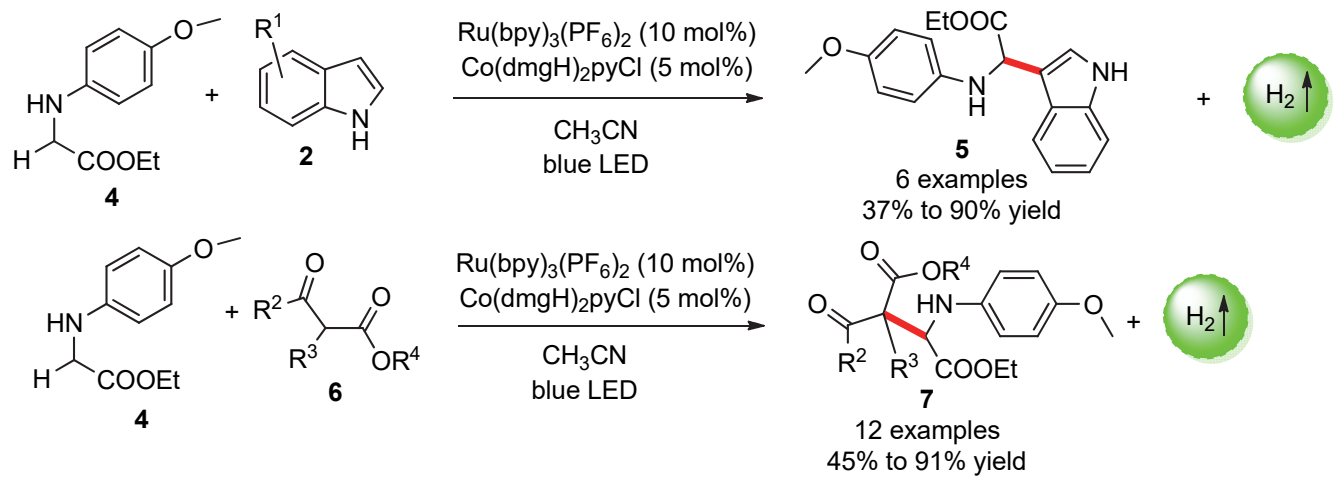

图式 $6 \alpha$-氨基酸衍生物的光催化偶联放氢反应

Scheme 6 Photocatalytic hydrogen-evolution coupling reaction of $\alpha$-amino acid derivatives

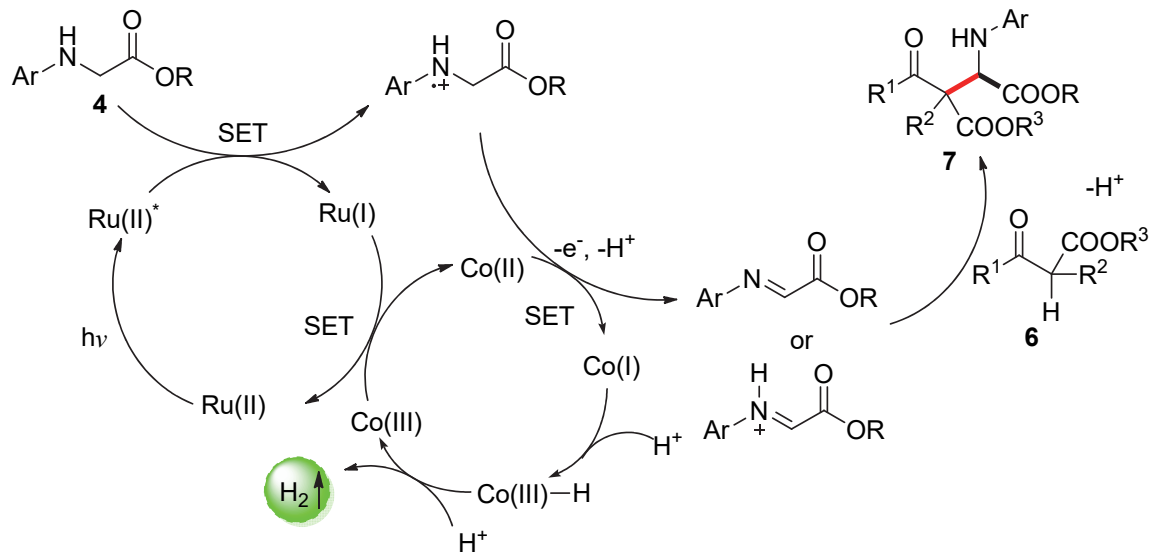

图式 7 双催化体系反应机理

Scheme 7 Reaction mechanism of the dual catalytic system

氧的 $\alpha-\mathrm{sp}^{3}$-碳的氧化电位较高, 因而相较于氮的 $\alpha$ 碳的氧化难度更大 ${ }^{[32 \sim 34]}$, 为了实现这种类型的 $\mathrm{C}\left(\mathrm{sp}^{3}\right)$ $\mathrm{H}$ 活化, 通常需要化学计量的氧化剂例如 2,3-二氯-5,6二氰基-1,4-苯醌(DDQ)或加入过氧化物来除去醚 $\alpha$-碳的 电子和氢原子, 从而形成 $\alpha$-氧自由基或氧鎓中间体用于 随后的转化(Scheme 8$)^{[35 \sim 37]}$.

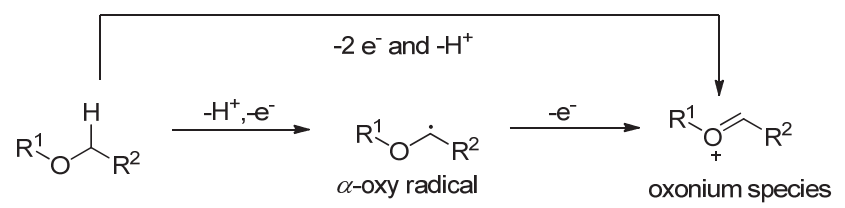

图式 8 使用氧化剂活化醚的 $\alpha-\mathrm{sp}^{3}$ 碳

Scheme 8 Activation of $\alpha$-sp $\mathrm{sp}^{3}$ carbon of ethers with oxidants

2015 年, 吴骊珠课题组通过使用强氧化性吅啶盐 光催化剂 $\left[\mathrm{Acr}^{+}-\mathrm{Mes} \mathrm{ClO}_{4}^{-}\right]$与 $\left[\mathrm{Co}\left(\mathrm{dmgBF}_{2}\right)_{2}(\mathrm{MeCN})_{2}\right]$ 催 化剂的双催化体系, 实现了含富电子芳环结构的醚的 $\alpha$-sp ${ }^{3}$-碳官能化，偶联产物最高收率达到 89\% (Scheme 9) ${ }^{[38]}$. 机理研究表明, 该反应中醚底物中的芳烃被激发 的光催化剂氧化后, 可以形成关键的苄基阳离子自由 基. 该阳离子自由基通过去质子化过程可以形成氧鎓中
间体. 加入的 $\mathrm{Cu}$ 盐在该体系中可以活化亲核试剂, 活 化的亲核试剂可以进攻氧鎓中间体从而生成目标产物.

含磷化合物在医药上具有重大应用价值，开发用于 高效合成各种含磷化合物的方法十分重要 ${ }^{[39,40]}$. 雷爱文 课题组 ${ }^{[41]}$ 在 2018 年报道了使用 $\left[\mathrm{Ru}(\mathrm{bpy})_{3}\left(\mathrm{PF}_{6}\right)_{2}\right]$ 光催化 剂和 $\left[\mathrm{Co}\left(\mathrm{dmgH}_{2} \mathrm{Cl}_{2}\right]\right.$ 催化剂对氮的相邻 $\mathrm{C}\left(\mathrm{sp}^{3}\right)-\mathrm{H}$ 活化 生成 $\alpha$-氨基膦酸盐 12 的反应，由于体系不含氧化剂，这 避免了磷的氧化副反应的发生(Scheme 10). 各种 $N$-烷 基苯胺衍生物，包括 $N, N$-二烷基苯胺、环胺和 $N$-苯基四 氢异喹啉, 可以以良好以上收率膦酰化生成一系列 $\alpha$-氨 基膦酸盐.

\section{2 活化 $\mathrm{sp}^{2}$-碳的光催化偶联放氢反应}

对 $\mathrm{sp}^{2}$-碳进行光催化氧化活化使之参与到偶联反应 也是光催化偶联放氢反应的一个很重要的应用领域. 2018 年, 雷爱文课题组 ${ }^{[42]}$ 使用 $\left[\mathrm{Arc}^{+}-\mathrm{Mes} \mathrm{ClO}_{4}^{-}\right]$光催化 剂和 $\left[\mathrm{Co}(\mathrm{dmgH})_{2}\left(4-\mathrm{NMe}_{2} \mathrm{py}\right) \mathrm{Cl}\right]$ 催化剂实现了富电子芳 烃和苯乙烯衍生物之间的交叉偶联放氢反应，偶联产物 收率最高达 99\% (Scheme 11A). 将苯乙烯类底物改为苯 丙炔类底物, 反应也能进行 (Scheme 11B), 但是脂肪族 


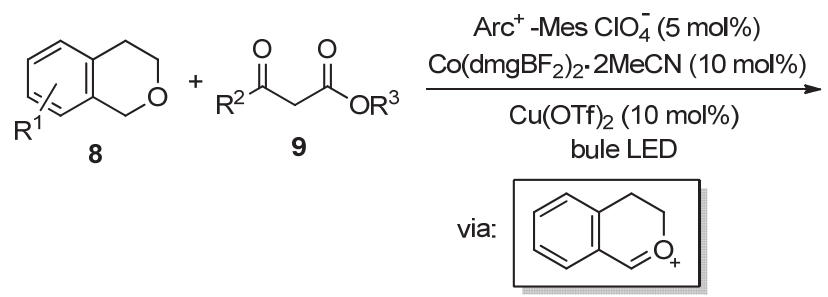

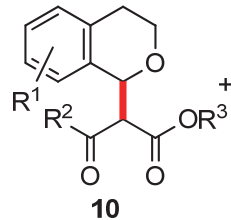

16 examples $55 \% \sim 76 \%$ yileds

图式 9 醚底物的光催化偶联放氢反应

Scheme 9 Photocatalytic hydrogen-evolution coupling reaction of ethers<smiles>[R]OCCN([R17])c1ccc[R]([H])c1</smiles>

11

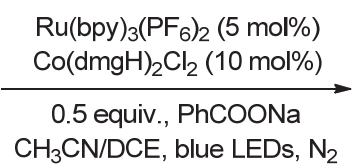

via:

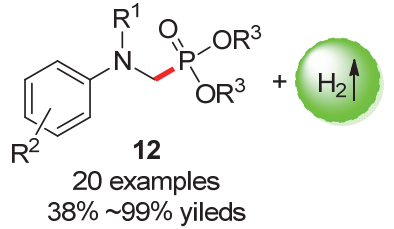

$38 \% \sim 99 \%$ yileds

图式 10 光催化偶联放氢反应制备 $\alpha$-氨基膦酸盐

Scheme 10 Preparation of $\alpha$-aminophosphonates by photocatalytic hydrogen-evolution coupling reaction

A<smiles>O=C(c1ccccc1)c1ccccc1</smiles>

13
$\mathrm{Acr}^{+}-\mathrm{Mes}^{-} \mathrm{ClO}_{4}^{-}(3 \mathrm{~mol} \%)$ $\mathrm{Co}(\mathrm{dmgH})_{2}\left(4-\mathrm{NMe}_{2} \mathrm{py}\right) \mathrm{Cl}(6 \mathrm{~mol} \%)$

via:

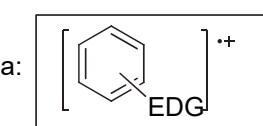

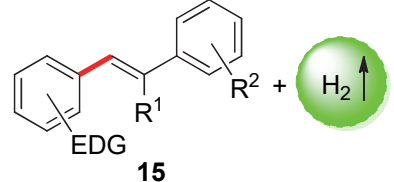

40 examples

$33 \% \sim 99 \%$ yield
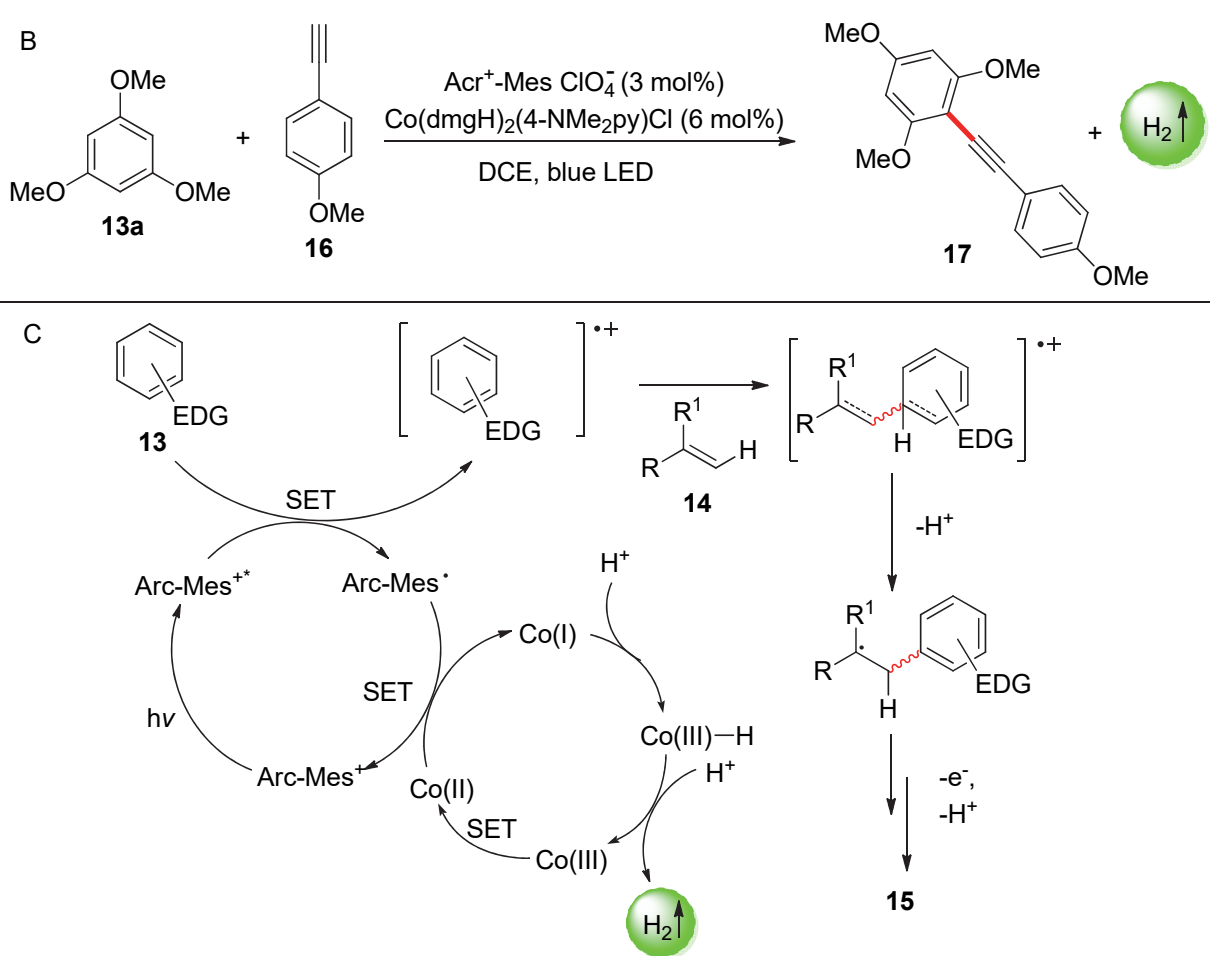

图式 11 富电子芳烃和苯乙烯/苯乙炔类物质的光催化偶联放氢反应以及反应机理

Scheme 11 Photocatalytic hydrogen-evolution coupling reaction of electron-rich aromatic hydrocarbons and styrenes/phenylacetylenes 
烯烃类底物则无法参与反应. 机理研究表明, 相较于苯 乙烯底物, 富电子芳烃底物更容易失去电子, 因而富电 子芳烃底物首先被激发态的光催化剂氧化生成阳离子 自由基中间体(Scheme 11C). 该中间体通过进攻苯乙烯 的烯烃键然后脱去质子生成自由基中间体. 该中间体通 过脱去质子和电子形成了目标偶联产物.

同年，雷爱文课题组 ${ }^{[43]}$ 报道了使用双催化体系实 现了芳香族亚胺底物和苯乙烯衍生物的光催化放氢 [4+2]环化生成 3,4-二氢异喹啉衍生物的反应. 该方式 可以以高区域选择性和非对映选择性合成一系列 3,4-二 氢异喹啉(Scheme 12). 研究表明反应中生成了关键的 烯烃阳离子自由基中间体. 通过进一步研究, 雷爱文等 人发现该反应体系也可以推广到苯乙烯衍生物和富电 子炔烃合成多取代的芳香族化合物的反应 ${ }^{[44]}$.

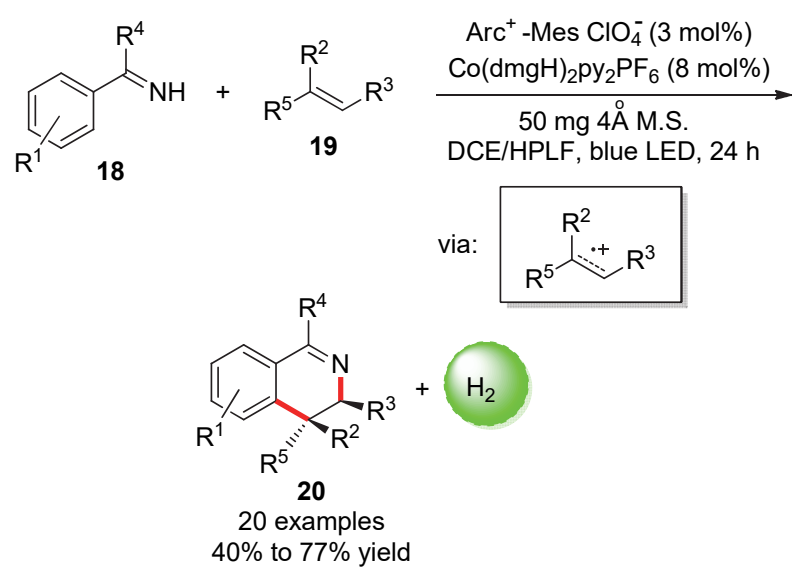

图式 12 光催化偶联合成 3,4-二氢异喹啉

Scheme 12 Photocatalytic hydrogen cross-coupling synthesis of 3,4-dihydroisoquinolines

含氮分子广泛存在于天然产物、合成中间体和功能 材料中, 超过 $90 \%$ 的药物分子具有胺基或氮杂环结 构 $^{[45]}$. 工业上制备含氮类化合物, 如苯胺, 芳基唑类化 合物等会产生大量的废料, 污染环境 ${ }^{[46]}$. 因此, 以经济 可持续的方式制备这些有价值的化合物始终处于有机 合成的研究领域前沿. 通过一步反应直接将简单芳烃 $(\mathrm{Ar}-\mathrm{H})$ 与唑类、仲胺类, 甚至是 $\mathrm{NH}_{3}$ 的交叉偶联生成 C-N 化合物的方法具有十分重要的经济价值.

2016 年, 吴网珠课题组 ${ }^{[47}$ 通过有机光催化剂和钴 肟催化剂的组合, 使用氨气在室温和 $\lambda>300 \mathrm{~nm}$ 光照条 件下将成功苯一步胺化为苯胺, 且不使用任何牺牲氧化 剂(Scheme 13), 在最佳条件下苯胺收率达 36\%. 研究发 现在该反应中没有形成多胺基取代苯副产物, 作者猜测 这是由于反应中生成的苯胺阳离子自由基会发生快速 的背电子转移回到苯胺从而抑制反应的进一步进行. 此 外, 作者发现该反应体系也可以进一步拓展到苯与水的 直接羟基化生成苯酚的反应, 收率高达 $90 \%$. 含吸电子
取代的底物也能参与反应得到取代苯酚，同样的，多羟 基取代的副产物也不会生成. 由于无氧气和牺牲剂参 与，这种交叉偶联放氢反应对于氧化敏感的底物的特别 有用.

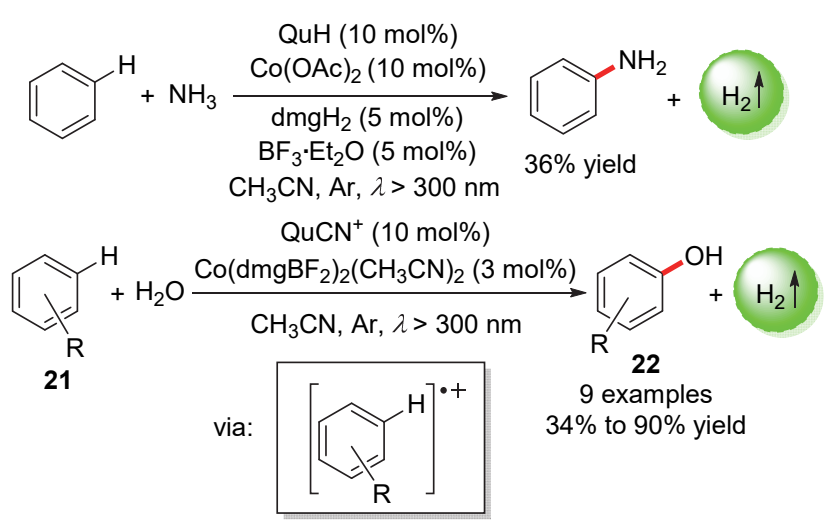

图式 13 苯的直接光催化偶联放氢合成苯胺/苯酚

Scheme 13 Direct photocatalytic hydrogen-evolution coupling of benzenes to anilines/phenols

芳基唑类化合物是非常普遍的含氮化合物，在农业 化学和生物制药领域具有特殊地位, 在温和条件下直接 使用简单芳烃 $(\mathrm{Ar}-\mathrm{H})$ 与唑类化合物偶联无疑是最经济 的方法 ${ }^{[48]} .2017$ 年, 雷爱文课题组 ${ }^{[49]}$ 使用鲐啶盐光催化 剂和金属钴肜催化剂的组合，成功实现了富电子芳烃的 无氧化剂 $\mathrm{C}\left(\mathrm{sp}^{2}\right)-\mathrm{H}$ 胺化，偶联产物最高收率达 $99 \%$, 且芳烃的 $\mathrm{sp}^{3}$-碳键不受影响(Scheme 14). 该方法可在无 氧化剂的条件下合成各种芳基唑类化合物. 机理研究表 明，该反应也是通过生成芳烃阳离子自由基中间体进行 的，生成的不同阳离子自由基的比例决定了胺化产物的 选择性.

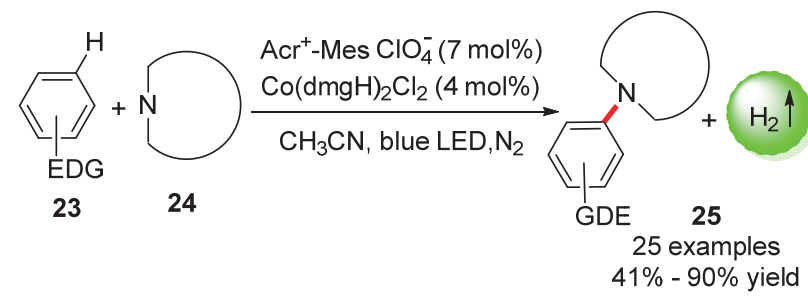

图式 14 光催化偶联放氢合成芳基唑类化合物

Scheme 14 Photocatalytic hydrogen-evolution coupling synthesis of aryl azoles

咪唑并吡啶是重要的稠合双环 $5 \sim 6$ 元杂环结构, 在药物化学中被广泛应用 ${ }^{[50,51]}$. 雷爱文课题组 ${ }^{[52]}$ 通过使 用浐啶盐光催化剂和钴豚催化剂的双催化体系, 实现了 对咪唑杂环的直接和区域选择性官能化 (Scheme 15). 一系列唑类衍生物和咪唑并吡啶底物都能在该反应体 系中以极高收率得到产物. 同时, 苯并 [d]-咪唑并[2,1- $b]$ 噻唑底物也可以以中等收率得到目标产物. 该反应中, 激发的光催化剂可以通过氧化咪唑杂环生成阳离子自 

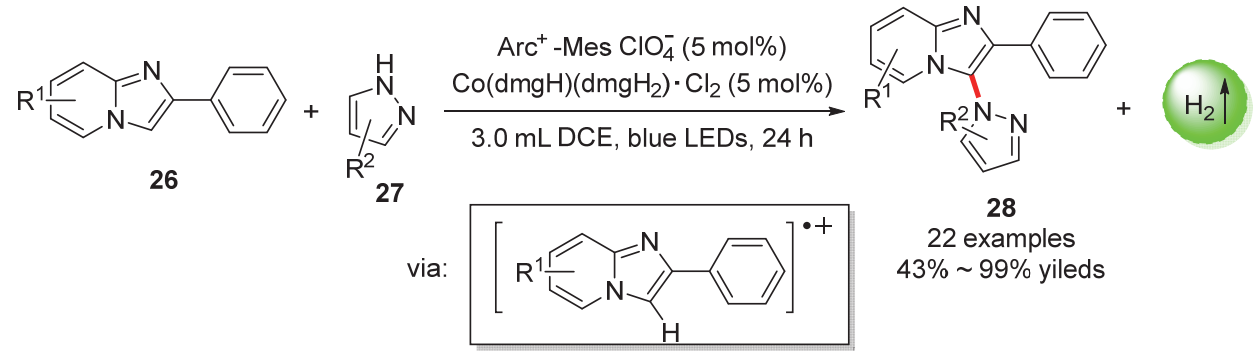

22 examples $43 \% \sim 99 \%$ yileds
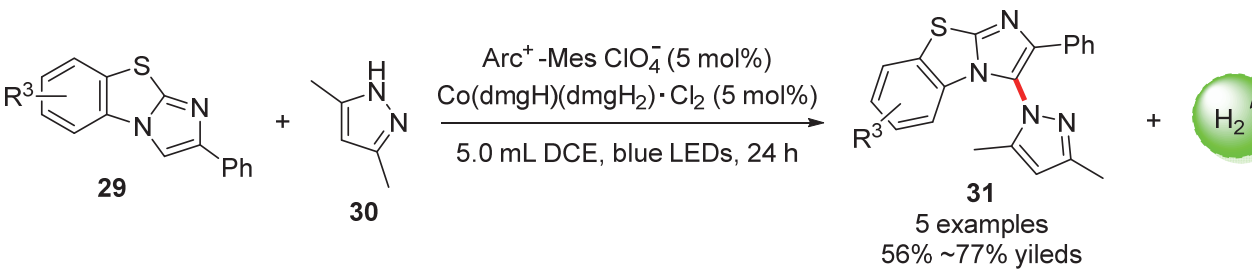

$56 \% \sim 77 \%$ yileds

图式 15 光催化偶联放氢反应合成咪唑并吡啶

Scheme 15 Synthesis of imidazopyridines by photocatalytic hydrogen-evolution coupling reaction

由基中间体，该中间体进一步参与反应.

通过使用强氧化性光催化剂氧化芳环生成阳离子 自由基这种策略, 雷爱文课题组 ${ }^{[53]}$ 还报道了富电子芳 烃(甲基芳烃, 茴香醚, 多环芳烃, 杂芳族化合物, 苯胺) 的 $\mathrm{C}\left(\mathrm{sp}^{2}\right)-\mathrm{H}$ 键膦酰化反应. 该反应不需要过量的膦酰 化试剂, 进一步展现了这种催化策略的应用潜力.

吲哚是一种重要的杂环化合物, 广泛存在于天然产 物、药物、农用化学品中 ${ }^{[54 ~ 57]}$. 吴网珠课题组 ${ }^{[58]}$ 在 2016 年报道了使用催化量的光催化剂 $\left[\operatorname{Ir}(\mathrm{ppy})_{3}\right]$ 和钴肟催化 剂 $\left[\mathrm{Co}(\mathrm{dmgH})_{2}\left(4-\mathrm{CO}_{2} \mathrm{Mepy}\right) \mathrm{Cl}\right]$ 的双催化体系将 $\mathrm{N}$-芳基 烯胺底物分子转化为吲哚 $\mathbf{3 3}$ 的反应(Scheme 16). 该反 应条件温和, 底物范围广, 为各种取代吲哚的合成提供 了新的思路. 在该反应里, 底物 $\mathbf{3 2}$ 上的 $\mathrm{N}$ 原子通过光催 化氧化并失去质子生成中间体 32a $\mathbf{a}^{\circ}$, 该中间体具有共振 体 32b'，这使得烯烃上的 $\mathrm{sp}^{2}$ 碳活化，发生环化反应.
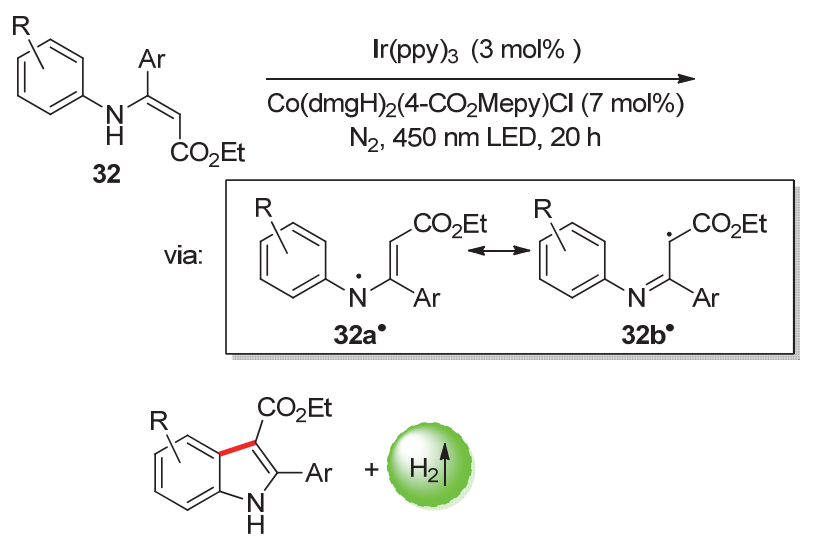

33

22 examples

$25 \% \sim 95 \%$ yiled

图式 16 光催化偶联放氢反应制备吲哚

Scheme 16 Preparation of rutheniums by photocatalytic hydrogen-evolution coupling reaction

\section{3 活化杂原子的偶联放氢反应}

通过对杂原子 $(O 、 N 、 S)$ 进行光催化氧化从而生成 具备亲电性的杂原子自由基, 可以实现分子内的偶联放 氢反应. 同样的, 这类反应不需要添加任何氧化剂.

由于金属与氧元素的 HOMO 和 LUMO 之间较高的 能垒, $\mathrm{C}-\mathrm{H}$ 官能化形成 $\mathrm{C}-\mathrm{O}$ 键在金属催化中受到的关 注较少 ${ }^{[59]}$. 近年来, 过渡金属催化的羧酸的氧化脱氢交 叉偶联技术推进了 $\mathrm{C}-\mathrm{O}$ 键的构建, 但必须加入氧化剂 和牺牲剂限制了反应的适用性 ${ }^{[60,61]} .2018$ 年, 朱成建课 题组 ${ }^{[62]}$ 使用了含 $\left[\mathrm{Arc}^{+}-\mathrm{Mes} \mathrm{BF}_{4}{ }^{-}\right]$光催化剂和 $[\mathrm{Co}-$ $\left.(\mathrm{dmgH})_{2} \mathrm{pyCl}\right]$ 催化剂的双催化体系, 成功实现了无氧化 剂和牺牲剂条件下苯的 $\mathrm{C}\left(\mathrm{sp}^{2}\right)-\mathrm{H}$ 官能化形成内酯的反 应(Scheme 17). 该合成方式具有好的底物适应性、官能 团耐受性和高产率的优点, 这给无氧化剂体系构建 C$\mathrm{O}$ 键提供了新的策略.

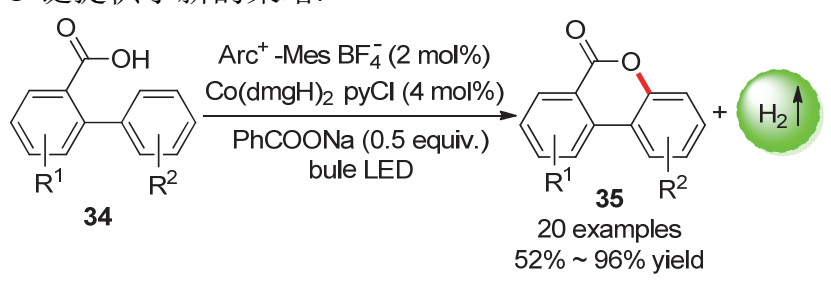

图式 17 羧酸的光催化偶联放氢反应

Scheme 17 Photocatalytic hydrogen-evolution coupling reaction of carboxylic acids

机理研究表明, 在紧凑型苂光灯(CFL Light)产生的 可见光照射下, 光催化剂 $\left[\mathrm{Arc}^{+}-\mathrm{Mes} \mathrm{BF}_{4}{ }^{-}\right]$可以产生长寿 命激发态 $[\mathrm{Acr}-\mathrm{Mes}]^{+*}$, 底物在存在碱(苯甲酸钠)的情况 下氧化峰电位得到降低, 因而可以通过与 $[\mathrm{Acr}-\mathrm{Mes}]^{+*}$ 发 生单电子转移 (SET) 过程以生成芳酰氧基自由基 (Scheme 18). 芳酰氧基自由基再经历: (1)分子内自由基 加成, (2)与 $\mathrm{Co}(\mathrm{III})$ 发生单电子转移, (3) 脱去氢质子. 最 
终生成了产物.

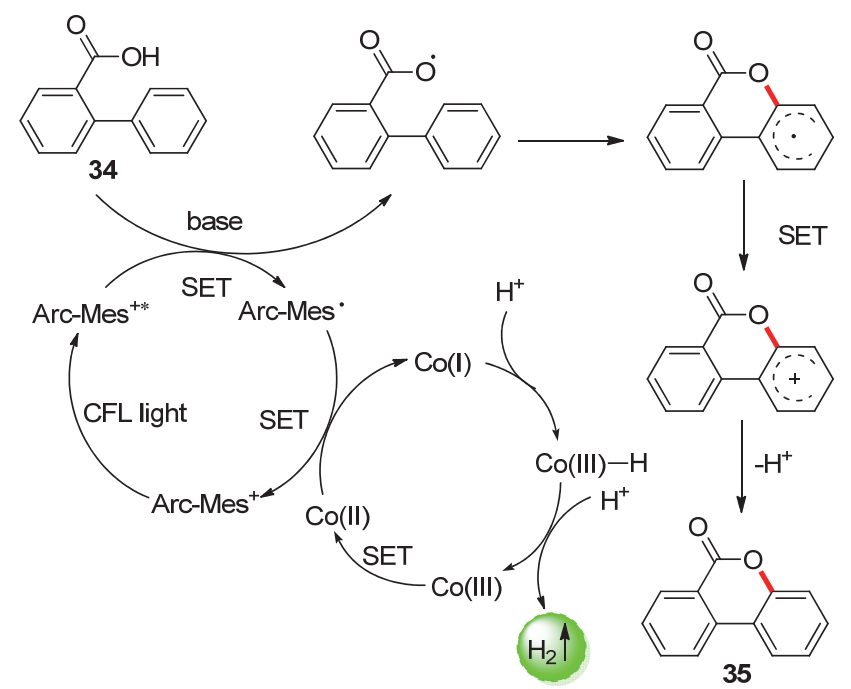

图式 18 羧酸的分子内光催化偶联放氢反应机理

Scheme 18 Mechanism of intramolecular photocatalytic hydrogen-evolution coupling reaction of carboxylic acids

$\mathrm{C}-\mathrm{S}$ 键常见于重要的药物和天然生物活性化合物 中 ${ }^{[63]} .2015$ 年, 吴骊珠等 ${ }^{[64]}$ 报道了芳香族化合物的分子 内偶联放氢生成硫醚的反应. 类似的, 通过在体系内加 入合适的碱可以活化底物, 谷氨酸钠对收率的提升特别 有效. 各种类型的硫代苯甲酰苯胺衍生物底物 36 可以 以良好的收率生成苯并噻唑类产物, 并且仅产生 $\mathrm{H}_{2}$ 作 为副产物(Scheme 19). 而通过向反应体系中加入硝基 苯, 可以以一锅法利用产生的 $\mathrm{H}_{2}$ 同时生成苯胺. 这种偶 联放氢反应可以应用于带有苯并噻唑结构(可用于抗肿 瘤药物)的生物活性分子的合成.

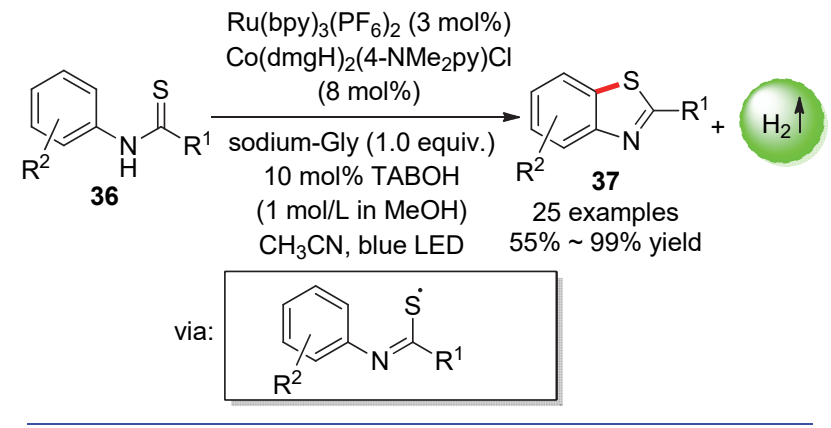

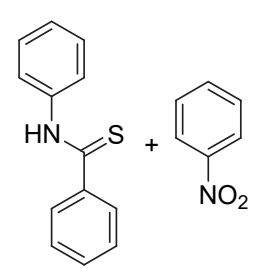

$36 a$

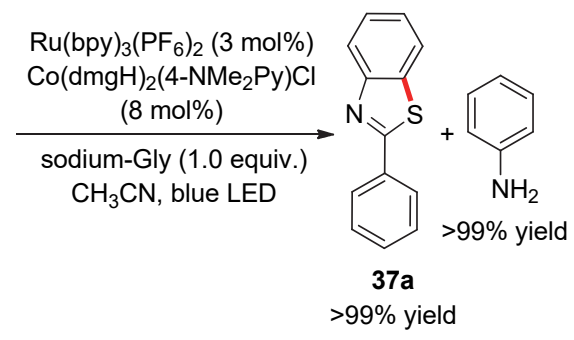

图式 19 光催化偶联放氢反应合成硫醚类物质

Scheme 19 Photocatalytic hydrogen-evolution coupling synthesis of sulfides
内磺酰胺结构是许多具有生物活性的天然产物和 药物相关化合物中常见的杂环组成部分，因此能以简单 的方法合成新颖的含内磺酰胺结构的化合物十分有必 要 ${ }^{[65]} .2016$ 年, 肖文精课题组 ${ }^{[66]}$ 报道了一种在无外部氧 化剂条件下的以可见光光催化 $\beta, \gamma$-不饱和腙化合物 $\mathbf{3 8}$ 生成 5 元 exo- $\beta, \gamma$-不饱和腙 39 的方法. 可以合成各种生 物学上有用的二氢吡唑稠合的苯并内磺酰胺类化合物. 各种 $\beta, \gamma$-不饱和腙底物都可以被很好地耐受(Scheme 20).

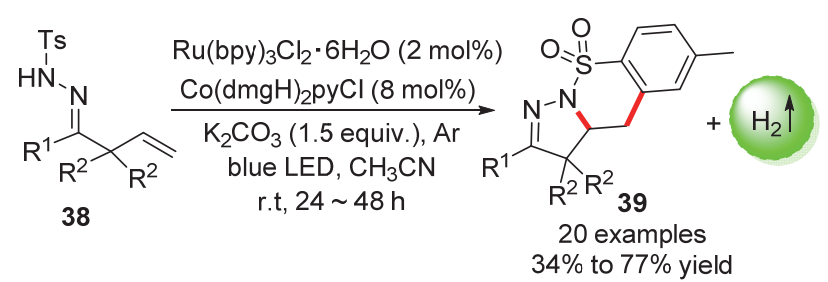

图式 205 元 exo- $\beta, \gamma$-不饱和腙化合物的合成 Scheme 20 Synthesis of 5-element exo- $\beta, \gamma$-unsaturated rutheniums

机理研究表明，该反应是由可见光诱导的 $\mathrm{N}$ 自由基 引发的级联 $\mathrm{C}-\mathrm{N} / \mathrm{C}-\mathrm{C}$ 偶联反应(Scheme 21). 反应中 首先生成的 $\mathrm{N}$-自由基中间体 B 通过连续 2 次自由基加 成反应生成了中间体 $\mathbf{D}$. 中间体 $\mathbf{D}$ 再通过与 $\mathrm{Co}(\mathrm{II})$ 的单 电子转移一质子脱去过程, 生成目标产物.

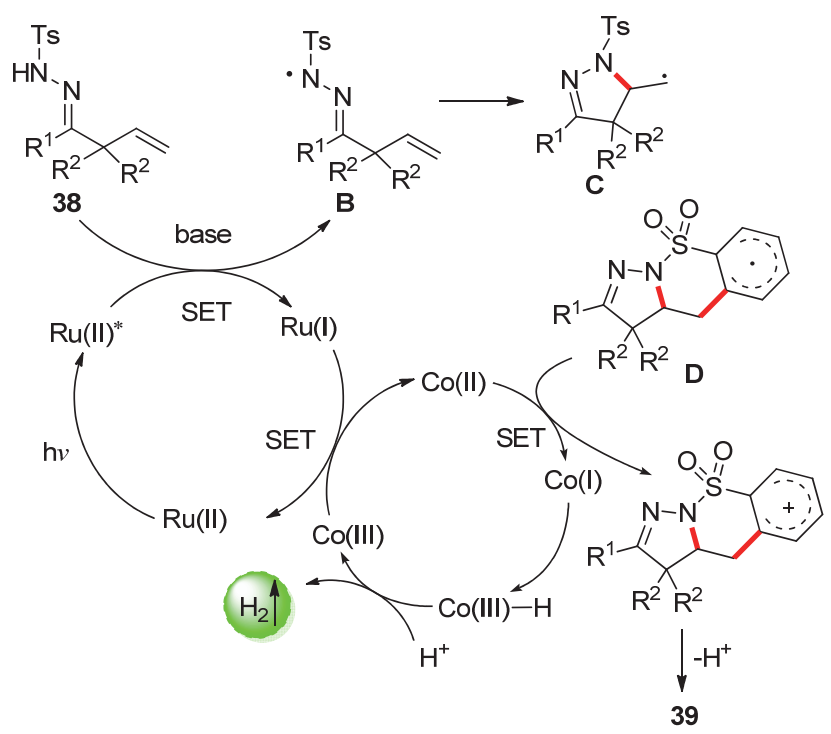

图式 21 双催化反应机理

Scheme 21 Reaction mechanism of the dual catalytic system

2018 年, 李洋课题组 ${ }^{[67]}$ 报道了通过可见光光催化 氧化使得双(4-甲基苯基)甲亚胺的 $\mathrm{N}-\mathrm{H}$ 键裂解形成亚 胺基自由基，用于合成异喹啉和相关的多芳烃化合物的 反应(Scheme 22). 机理研究表明，该反应是由亚胺基自 
由基引发的级联 $\mathrm{C}-\mathrm{N} / \mathrm{C}-\mathrm{C}$ 偶联反应.
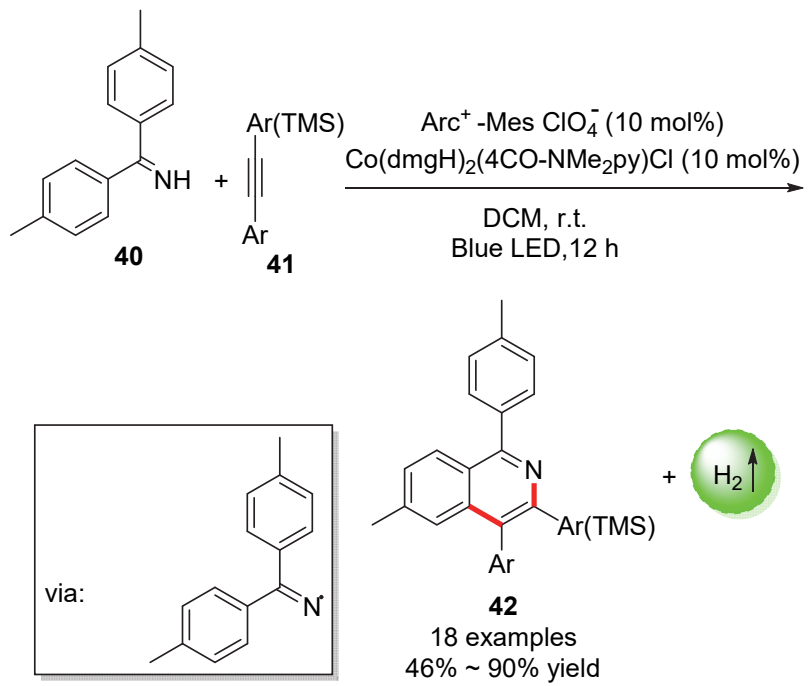

图式 22 异喹啉以及相关的多芳烃化合物的合成 Scheme 22 Synthesis of isoquinolines and related polyaromatic compounds

\section{4 芳构化放氢反应}

烯烃广泛存在于各类化合物中, 且可用于复杂天然 产物和药物衍生合成 ${ }^{[68,69]}$. 饱和烷基的脱氢可以使得不 饱和键的引入位置具有灵活选择性. 传统的脱氢策略需 要贵金属催化, 如 Bergman ${ }^{[70]}$ 和 Graham $^{[71]}$ 等开发了使 用低价铱配合物氧化加成 $\mathrm{C}-\mathrm{H}$ 键的体系(Scheme 23A). 天然去饱和酶体系也可以在酶活性温度下进行氢原子 的转移, 但是这种转化需要化学计量的氧化剂, 如天然 铁基去饱和酶系统引发的底物氢原子转移反应 ${ }^{[72 ~ 74]}$ (Scheme 23B).

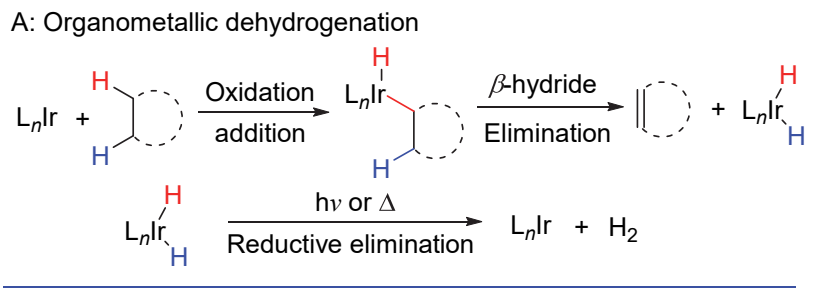

B: Enzymatic desaturation

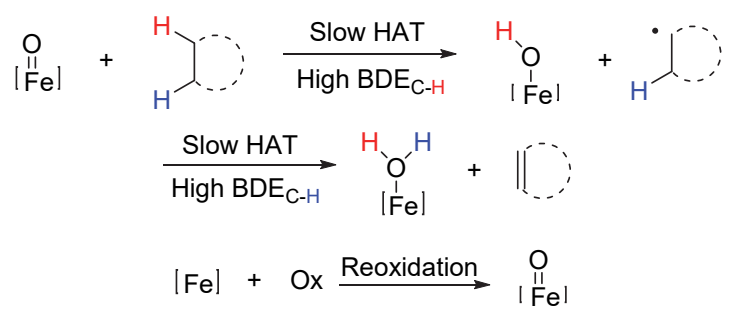

图式 23 饱和烷基的催化脱氢策略

Scheme 23 Catalytic dehydrogenation strategy for saturated alkanes
2015 年, Sorensen 等 ${ }^{[75]}$ 使用四丁基铵十聚铇酸盐 (TBADT)和钴肜催化剂的双催化体系, 近紫外光照射下 成功实现了一系列烷烃类底物和醇类底物的无受体脱 氢, 这是有所报道的烷烃室温条件无受体脱氢的第一个 例子.

2017 年, 李洋课题组 ${ }^{[76]}$ 报道了以 $\mathrm{Ru}$ 光催化剂和钴 肟催化剂的双催化体系催化的 $\mathrm{N}$-杂环化合物的无受体 芳构化放氢反应(Scheme 24). 在蓝色 LED 照射下, 收率 最高可达 99\%，该方法具有较高的通用性.

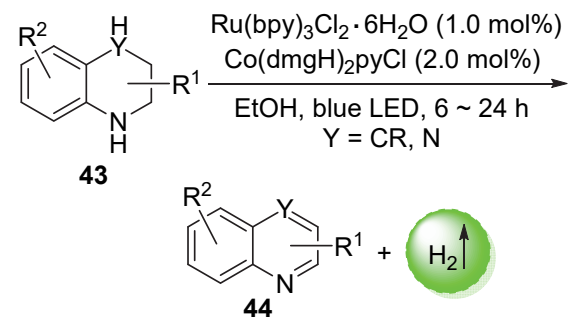

25 examples $9 \% \sim 99 \%$ yield
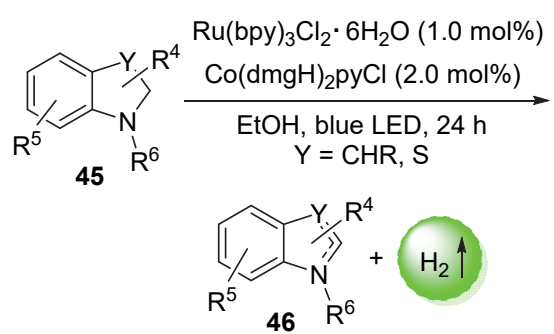

15 examples

$82 \% \sim 95 \%$ yield

图式 $24 \mathrm{~N}$-杂环化合物的光催化无受体芳构化放氢反应

Scheme 24 Photocatalytic non-receptor hydrogen-evolution aromatization reaction of $\mathrm{N}$-heterocyclic compounds

机理研究表明，芳构化放氢的反应的机理类似于交 叉偶联放氢反应, 也是通过三个单电子转移过程完成了 底物的放氢和光催化剂/催化剂的再生过程. 不同的是, $\mathrm{Co}(\mathrm{II})$ 淬灭激发态光催化剂的能力比 $\mathrm{N}$-杂环化合物更 强. 因此在这里, 反应主要通过 $\mathrm{Ru}(\mathrm{bpy})_{3}^{2+}$ 的氧化淬灭 途径进行而非偶联放氢反应中常见的还原淬灭途径. N杂环化合物可通过与 $\mathrm{Ru}(\mathrm{bpy})_{3}^{3+}$ 进行电子转移而活化 (Scheme 25).

Balaraman 等 ${ }^{[77]}$ 通过研究发现, 将上述芳构化放氢 的反应体系改为纯水体系后, $\mathrm{N}$-杂环化合物也能以非常 好的收率得到芳构化产物. 这给合成各种 $\mathrm{N}$-杂环芳烃 如喹啉、喹喔啉、吟啶和吲哚衍生物提供了更加绿色环 保的策略(Scheme 26).

2017 年, Kojima 等 ${ }^{[78]}$ 开发了一种可用于 N-杂环化 合物和四氢化菜的无受体脱氢的混合催化体系. 通过使 用鲐啶盐光催化剂和过渡金属 Pd 催化剂的双催化体系, 可以使得 $\mathrm{N}$-杂环化合物脱氢芳构化. 体系中额外加入 


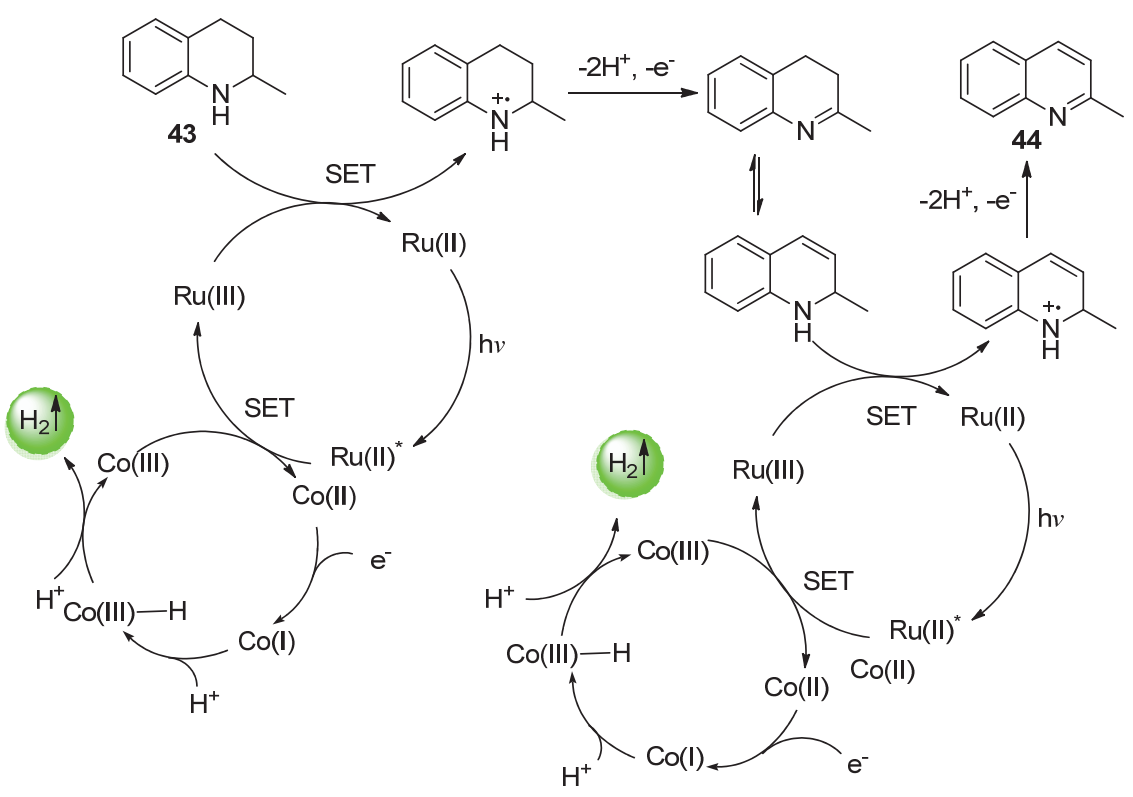

图式 $25 \mathrm{~N}$-杂环化合物的光催化芳构化放氢反应机理

Scheme 25 Photocatalytic hydrogen-evolution aromatization mechanism of N-heterocyclic compounds<smiles>[R]CNC1=CC=[R1]C=C2CCCC21</smiles>

47 $\underset{\mathrm{Co}(\mathrm{dmgH})_{2}\left(4-\mathrm{CO}_{2} \mathrm{MePy}\right) \mathrm{Br}(2.5 \mathrm{~mol} \%)}{\text { Water, r.t., } \mathrm{Ar}}$<smiles>[R]c1ccc2cc[R1]cc2n1</smiles>

48

10 examples $37 \% \sim 96 \%$ yield<smiles></smiles>

$\mathrm{Ru}(\mathrm{bpy})_{3} \mathrm{Cl}_{2}(1.0 \mathrm{~mol} \%)$ $\mathrm{Co}(\mathrm{dmgH})_{2}\left(4-\mathrm{CO}_{2} \mathrm{MePy}\right) \mathrm{Br}(2.5 \mathrm{~mol} \%)$

49 $12 \mathrm{~h}$, blue LED<smiles>[R]C1=CC=[R1]c2[nH]c3ccc1[nH]c2-3</smiles><smiles>[CH]1CCCC1</smiles>

8 examples $58 \% \sim 94 \%$ yield

图式 26 纯水体系 N-杂环化合物的光催化无受体芳构化放氢 反应

Scheme 26 Photocatalytic non-receptor hydrogen-evolution aromatization reaction of $\mathrm{N}$-heterocyclic compounds in water

一定量的 $\mathrm{KSbF}_{6}$ 后, 1-苯基四氢异喹啉(51) 可以在最佳 反应条件下以最高 $96 \%$ 的收率得到芳构化产物(Scheme 27A). 该体系也可以应用于 2,3-二氢吲哚衍生物的芳构 化反应.

在该反应里, 被光催化剂氧化生成的自由基中间体 可被金属催化剂 $\left(\mathrm{M}^{n}\right)$ 捕获以产生带有 $n+1$ 价的金属胺 中间体 $\left(\mathrm{M}^{n+1}\right)$, 该中间体可与光催化剂发生电子交换, 最后经历还原消除步骤以生成单烯烃产物. 该烯烃产物 可重复上述步骤从而生成芳构化产物(Scheme 27B).
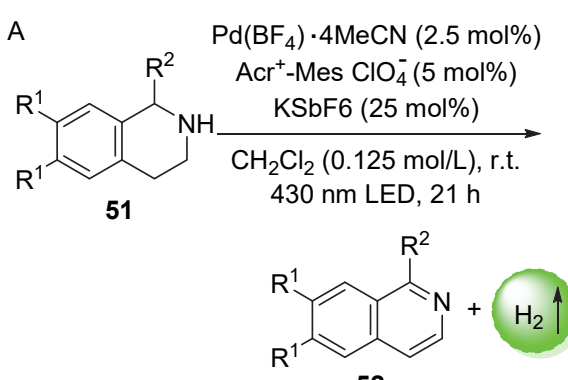

5 examples $41 \%$ to $96 \%$ yields

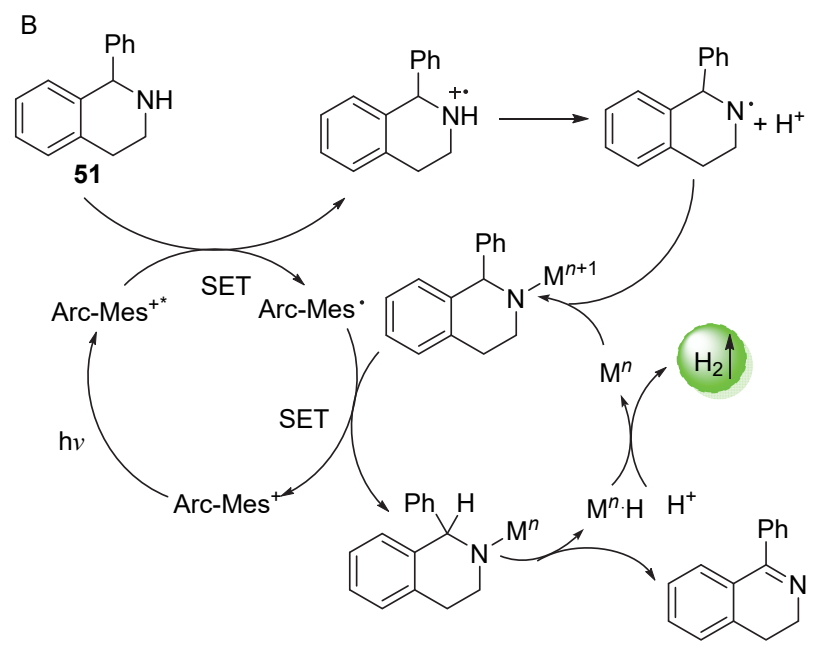

图式 $27 \mathrm{~N}$-杂环化合物的光催化析氢芳构化反应以及反应机 理

Scheme 27 Photocatalytic hydrogen-evolution aromatization reaction of N-heterocyclic compounds and reaction mechanism

而通过向反应体系中加入硫代磷酰亚胺有机催化 
剂形成三元混合催化体系后，该方法甚至可以实现四氢 化菜的脱氢反应，最高收率可达 $82 \%$ (Scheme 28). 机理 研究表明, 加入的硫醇 55 (RSH) 可以与激发的光催化剂 发生单电子转移(SET)过程生成硫自由基 $\mathbf{R S}^{\circ}$, 四氢化 䒺可与该自由基 $\left(\mathbf{R S}^{\circ}\right)$ 反应产生苄位自由基. 类似的, 苄 位自由基可与 $\mathrm{Pd}$ 金属配位. 该反应条件温和, 该反应对 不同底物具有较高的耐受性，具有进一步发展的潜力.
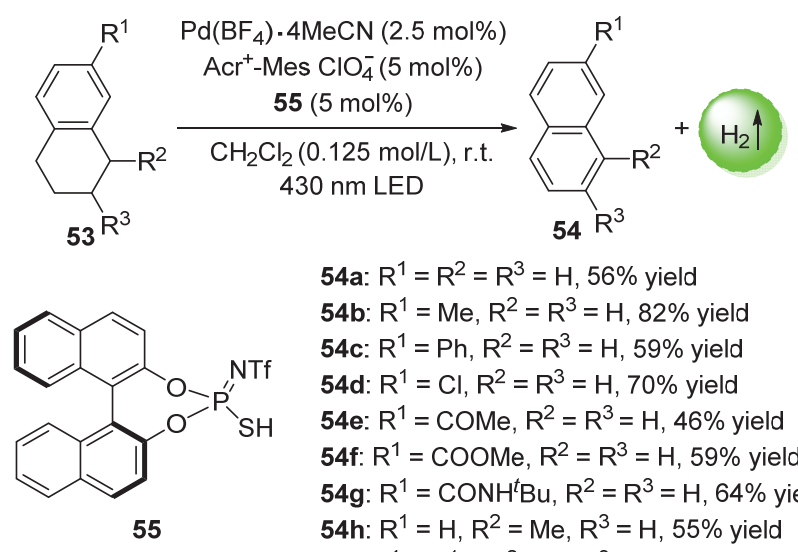

54a: $R^{1}=R^{2}=R^{3}=H, 56 \%$ yield 54b: $R^{1}=$ Me, $R^{2}=R^{3}=H, 82 \%$ yield 54c: $R^{1}=P h, R^{2}=R^{3}=H, 59 \%$ yield 54d: $R^{1}=\mathrm{Cl}, \mathrm{R}^{2}=\mathrm{R}^{3}=\mathrm{H}, 70 \%$ yield 54e: $R^{1}=$ COMe, $R^{2}=R^{3}=H, 46 \%$ yield 54f: $R^{1}=$ COOMe, $R^{2}=R^{3}=H, 59 \%$ yield 54g: $R^{1}=C^{\prime} H^{t} B u, R^{2}=R^{3}=H, 64 \%$ yield 54h: $R^{1}=H, R^{2}=$ Me, $R^{3}=H, 55 \%$ yield 54i: $R^{1}=R^{1}=R^{2}=H, R^{3}=$ Me, $52 \%$ yield

图式 28 四氢化䒺的光催化析氢芳构化反应

图式 28 Photocatalytic hydrogen-evolution aromatization of tetrahydronaphthalenes

值得一提的是, Kojima 等 ${ }^{[79]}$ 通过进一步研究发现, 将反应体系改为鲐啶盐光催化剂、 Ni(II)催化剂和硫代 磷酸有机催化剂的三元催化体系, 也能实现四氢化萗甚 至是富电子环己烷、富电子环已烯的直接芳构化反应. 这是报道的于可见光温和条件下的非贵金属催化烷烃 类无受体脱氢芳构化的第一个例子.

\section{5 总结和展望}

通过使用可见光介入的光催化偶联/芳构化放氢这 种合成策略, 可以实现一系列不同的、热力学上有难度 的官能化反应. 这类反应的反应条件温和, 不需要加入 化学计量的氧化剂和电子牺牲剂, 具有绿色、高效、安 全等优势, 这为合成一些医药、功能材料提供了新的方 法. 虽然目前该合成策略仍存在一些局限性, 如难以活 化惰性的碳或杂原子, 合成方式的适用性较差. 同时, 对于复杂的分子以及天然产物, 该合成方法仍然处于研 究初级阶段. 挑战虽然存在, 但是由于该催化方式的独 特性和潜力, 相信该合成策略相信能够得到进一步的优 化和拓展, 能用于更多的催化反应中, 适用于更多种类 的底物.

\section{References}

[1] Shaw, M. H.; Twilton, J.; MacMillan, D. W. J. Org. Chem. 2016, 81,6898

[2] Karkas, M. D.; Porco, J. A., Jr.; Stephenson, C. R. Chem. Rev. 2016,
$116,9683$.

[3] Shvydkiv, O.; Nolan, K.; Oelgemoller, M. Beilstein J. Org. Chem. 2011, 7, 1055

[4] Xuan, J.; Xiao, W. -J. Angew. Chem. Int. Ed. 2012, 51, 6828.

[5] Luo, S. -P.; Chen, N.-Y.; Sun, Y.-Y.; Xia, L.-M.; Wu, Z.-C. Junge, H.; Beller, M.; Wu, Q.-A. Dyes Pigm. 2016, 134, 580.

[6] Takeda, H.; Ishitani, O., Coord. Chem. Rev. 2010, 254, 346

[7] Chen J.-X.; Miao, Y.-Y. Nat. Gas Chem. Ind. 2019, 44, 116 (in Chinese).

(陈嘉欣，苗媛媛，天然气化工(C1 化学与化工), 2019, 44, 116.)

[8] Xie, J.; Jin, H.; Xu, P.; Zhu, C. Tetrahedron Lett. 2014, 55, 36.

[9] Chen, J.; Cen, J.; Xu, X.; Li, X. Catal. Sci. Technol. 2016, 6, 349.

[10] Romero, N. A.; Nicewicz, D. A. Chem. Rev. 2016, 116, 10075.

[11] Heck, R. F.; Nolley, J. P. J. Org. Chem. 1972, 37, 2320.

[12] Tamao, K. K. Y.; Sumitani, K. J. Am. Chem. Soc. 1972, 26, 9268.

[13] Hiyama, T.; Sawahata, M.; Obayashi, M. Chem. Informationsdienst 1984, 15.

[14] Zhang, W.; Dai, J.; Xu, H. Chin. J. Org. Chem. 2015, 35, 1820 (in Chinese). (张文曼, 戴建军, 许华建, 有机化学, 2015, 35, 1820.)

[15] Cao, S.-S. Chem. Bull. 2019, 82, 684 (in Chinese). (曹莎莎，化学通报, 2019, 82, 684.)

[16] Yuan, D.; Zhang, Q.; Liao, S.; Xiong, W.; Yuan, L.; Cai, Q.; Yang, M.; Li, X.; Jiang, Y.; Liu, Y.; Li, P.; Xu, Z.; Sun, P.; Geng, H. Chin. J. Org. Chem. 2015, 35, 961 (in Chinese).

(袁定重, 张庆华, 廖世军, 熊文文, 元利刚, 蔡奇胜, 杨梦梅, 李雄, 蒋烨佳, 刘妍, 李萍, 徐贞帅, 孙盼盼, 耿会玲, 有机化 学, 2015, 35, 961.)

[17] Girard, S. A.; Knauber, T.; Li, C. J. Angew. Chem., Int. Ed. 2014, 53,74 .

[18] Tang, S.; Zeng, L.; Lei, A.-W. J. Am. Chem. Soc. 2018, 140, 13128.

[19] Chen, B.; Wu, L.-Z.; Tung, C.-H. Acc. Chem. Res. 2018, 51, 2512.

[20] Zhong, J.-J.; Meng, Q.-Y.; Chen, B.; Tung, C.-H.; Wu, L.-Z. Acta Chim. Sinica 2017, 75, 34 (in Chinese).

(钟建基, 孟庆元, 陈涁, 佟振合, 吴骊珠，化学学报, 2017, 75, 34.)

[21] Meng, Q.-Y.; Zhong, J.-J.; Liu, Q.; Gao, X.-W.; Zhang, H.-H.; Lei, T.; Li, Z.-J.; Feng, K.; Chen, B.; Tung, C.-H.; Wu, L.-Z. J. Am. Chem. Soc. 2013, 135, 19052.

[22] Zhang, P., Ph.D. Dissertation, Dalian University of Technology, Dalian, 2011 (in Chinese). (张盼, 博士论文, 大连理工大学, 大连, 2011.)

[23] Schrauzer, G. N. Acc. Chem. Res. 1968, 1, 97.

[24] Connolly, P.; Espenson, J. H. Inorg. Chem. 1986, 25, 2684.

[25] Pantani, O.; Naskar, S.; Guillot, R.; Millet, P.; AnxolabéhèreMallart, E.; Aukauloo, A. Angew. Chem., Int. Ed. 2008, 47, 9948.

[26] Razavet, M.; Artero, V.; Fontecave, M. Inorg. Chem. 2005, 44, 4786.

[27] Baffert, C.; Artero, V.; Fontecave, M., Inorg. Chem. 2007, 46, 1817.

[28] Hu, X.; Brunschwig, B. S.; Peters, J. C. J. Am. Chem. Soc. 2007, $129,8988$.

[29] Zhong, J.-J.; Meng, Q. Y.; Liu, B.; Li, X.-B.; Gao, X.-W.; Lei, T.; Wu, C.-J.; Li, Z.-J.; Tung, C.-H.; Wu, L.-Z. Org. Lett. 2014, 16, 1988.

[30] Zhong, J. J.; Wu, C.-J.; Meng, Q. Y.; Gao, X.-W.; Lei, T.; Tung, C. H.; Wu, L.-Z. Adv. Synth. Catal. 2014, 356, 2846.

[31] Gao, X. W.; Meng, Q.-Y.; Li, J.-X.; Zhong, J.-J.; Lei, T.; Li, X.-B.; Tung, C.-H.; Wu, L.-Z. ACS Catal. 2015, 5, 2391.

[32] Liu, C.; Zhang, H.; Shi, W.; Lei, A.-W. Chem. Rev. 2011, 111, 1780.

[33] Sun, C.-L.; Li, B.-J.; Shi, Z.-J. Chem. Rev. 2011, 111, 1293.

[34] Yeung, C. S.; Dong, V. M. Chem. Rev. 2011, 111, 1215.

[35] Zhang, S.-Y.; Zhang, F.-M.; Tu, Y.-Q. Chem. Soc. Rev. 2011, 40, 1937.

[36] Li, Z.; Yu, R.; Li, H. Angew. Chem., Int. Ed. 2008, 120, 7607.

[37] Liu, D.; Liu, C.; Li, H.; Lei, A.-W. Chem. Commun. 2014, 50, 3623.

[38] Xiang, M.; Meng, Q.-Y.; Li, J.-X.; Zheng, Y.-W.; Ye, C.; Li, Z.-J.; Chen, B.; Tung, C. H.; Wu, L.-Z. Chemistry 2015, 21, 18080

[39] Rezaei, Z.; Firouzabadi, H.; Iranpoor, N.; Ghaderi, A.; Jafari, M. R.; 
Jafari, A. A.; Zare, H. R. Eur. J. Med. Chem. 2009, 44, 4266.

[40] Turski, L.; Schneider, H. H.; Neuhaus, R. Restor. Neurol. Neurosci. $2000,17,45$.

[41] Niu, L.; Wang, S.; Liu, J.; Yi, H.; Liang, X.-A.; Liu, T.; Lei, A.-W. Chem. Commun. 2018, 54, 1659.

[42] Hu, X.; Zhang, G.-D.; Bu, F.-X.; Luo, X.; Yi, K.-B.; Zhang, H.; Lei, A.-W. Chem. Sci. 2018, 9, 1521.

[43] Hu, X.; Zhang, G.; Bu, F.; Lei, A. Angew. Chem., Int. Ed. 2018, 57, 1286

[44] Zhang, G.; Lin, Y.; Luo, X.; Hu, X.; Chen, C.; Lei, A.-W. Nat. Commun. 2018, 9, 1225.

[45] Schlogl, R. Angew. Chem., Int. Ed. 2003, 42, 2004

[46] Karam, A. R.; Catarí, E. L.; López-Linares, F.; Agrifoglio, G.; Albano, C. L.; Díaz-Barrios, A.; Lehmann, T. E. Appl. Catal. 2005, $280,165$.

[47] Zheng, Y.-W.; Chen, B.; Ye, P.; Feng, K.; Wang, W.; Meng, Q.-Y.; Wu, L.-Z.; Tung, C.-H. J. Am. Chem. Soc. 2016, 138, 10080.

[48] Vicentini, C. B.; Romagnoli, C.; Andreotti, E. Agric. Food Chem. 2007, 55, 10331.

[49] Niu, L.; Yi, H.; Wang, S.; Liu, T.; Liu, J.; Lei, A.-W. Nat. Commun. 2017, 8, 14226 .

[50] Marson, C. M. Chem. Soc. Rev. 2011, 40, 5514.

[51] Baviskar, A. T.; Amrutkar, S. M.; Trivedi, N.; Chaudhary, V.; Nayak, A.; Guchhait, S. K.; Banerjee, U. C.; Bharatam, P. V.; Kundu, C. N. ACS Med. Chem. Lett. 2015, 6, 481.

[52] Chen, H.; Yi, H.; Tang, Z.; Bian, C.; Zhang, H.; Lei, A.-W. Adv. Synth. Catal. 2018, 360, 3220.

[53] Niu, L.; Liu, J.; Yi, H.; Wang, S.; Liang, X.-A.; Singh, A. K.; Chiang, C.-W.; Lei, A.-W. ACS Catal. 2017, 7, 7412.

[54] Janicki, S. Z.; Schuster, G. B. J. Am. Chem. Soc. 1995, 117, 8524

[55] Somei, M.; Yamada, F. J. Nat. Prod. 2004, 21, 278

[56] Somei, M.; Yamada, F. J. Nat. Prod. 2005, 22, 73.

[57] Kochanowska-Karamyan, A. J.; Hamann, M. T. Chem. Rev. 2010, 110,4489

[58] Wu, C.-J.; Meng, Q.-Y.; Lei, T.; Zhong, J.-J.; Liu, W.-Q.; Zhao, L.-M.; Li, Z.-J.; Chen, B.; Tung, C.-H.; Wu, L.-Z. ACS Catal. 2016, 6,4635 .
[59] Petersen, A. R.; Taylor, R. A.; Vicente-Hernandez, I.; Mallender, P. R.; Olley, H.; White, A. J.; Britovsek, G. J. J. Am. Chem. Soc. 2014, 136, 14089.

[60] Zhang, C.; Tang, C.; Jiao, N. Chem. Soc. Rev. 2012, 41, 3464.

[61] Liu, C.; Yuan, J.; Gao, M.; Tang, S.; Li, W.; Shi, R.; Lei, A.-W. Chem. Rev. 2015, 115, 12138.

[62] Zhang, M.-L.; Ruzi, R.; Li, N.; Xie, J.; Zhu, C. Org. Chem. Front. 2018, 5, 749 .

[63] Sun, Q, W. R.; Cai, S. J. Med. Chem. 2011, 54, 1126.

[64] Zhang, G.; Liu, C.; Yi, H.; Meng, Q.; Bian, C.; Chen, H.; Jian, J.-X.; Wu, L.-Z.; Lei, A.-W. J. Am. Chem. Soc. 2015, 137, 9273.

[65] Welsch, M. E.; , Snyder, S. A., Stockwell, B. R. Curr. Opin. Chem. Biol. 2010, 14, 347.

[66] Zhao, Q.-Q.; Hu, X.-Q.; Yang, M.-N.; Chen, J.-R.; Xiao, W.-J. Chem. Commun. 2016, 52, 12749.

[67] Tian, W.-F.; Wang, D.-P.; Wang, S.-F.; He, K.-H.; Cao, X.-P.; Li, Y. Org. Lett. 2018, 20, 1421.

[68] Dobereiner, G. E.; Crabtree, R. H. Chem. Rev. 2010, 110, 681.

[69] Voica, A. F.; Mendoza, A.; Gutekunst, W. R.; Fraga, J. O.; Baran, P. S. Nat. Chem. 2012, 4, 629

[70] Janowicz, A. H.; Bergman, R. G. J. Am. Chem. Soc. 1982, 104, 352.

[71] Hoyano, J. K.; Graham, W. A. G. J. Am. Chem. Soc. 1982, 104, 3723.

[72] Buist, P. H. Nat. Prod. Rep. 2004, 21, 249.

[73] Breslow, R.; Baldwin, S.; Flechtner, T.; Kalicky, P.; Liu, S.; Washburn, W. J. Am. Chem. Soc. 1973, 95, 3251.

[74] Bigi, M. A.; Reed, S. A.; White, M. C. Nat. Chem. 2011, 3, 216.

[75] West, J. G.; Huang, D.; Sorensen, E. J. Nat. Commun. 2015, 6, 10093.

[76] He, K.-H.; Tan, F.-F.; Zhou, C.-Z.; Zhou, G.-J.; Yang, X.-L.; Li, Y. Angew. Chem., Int. Ed. 2017, 56, 3080.

[77] Sahoo, M. K.; Balaraman, E. Green Chem. 2019, 21, 2119.

[78] Kato, S.; Saga, Y.; Kojima, M.; Fuse, H.; Matsunaga, S.; Fukatsu, A.; Kondo, M.; Masaoka, S.; Kanai, M. J. Am. Chem. Soc. 2017, 139, 2204.

[79] Fuse, H.; Kojima, M.; Mitsunuma, H.; Kanai, M. Org. Lett. 2018, $20,2042$.

(Cheng, F.) 